\title{
Ending HIV in America: Not Without the Power of Community
}

\author{
Ronald O. Valdiserri ${ }^{1}\left[\right.$ D . David R. Holtgrave ${ }^{2}$
}

Published online: 5 April 2019

(c) Springer Science+Business Media, LLC, part of Springer Nature 2019

One would be hard-pressed to think about the HIV epidemic, whether in the US or elsewhere, without bringing to mind the response of the communities who have been affected by the virus. In the earliest days of the US epidemic, activists from the gay community banded together to form volunteer-run community-based organizations (CBOs) to meet the needs of those sickened with this frightening, new disease-at a time when most public officials and policy makers ignored the epidemic [1-3]. Beyond the provision of much-needed support services, community activists were also instrumental in raising awareness about AIDS among the general public [4], educating individuals about strategies to reduce their risk of acquiring AIDS [5] and advocating for a more timely and well-funded governmental response to the epidemic [6].

As the epidemic progressed, it became increasingly apparent that actively involving those who were living with, at risk for or affected by the virus in governmental prevention and treatment efforts was necessary to ensure buy-in and support. An early expression of this reality can be found in the "Denver Principles" articulated in 1983 by a committee of people living with AIDS [7]. The principles stated that people with AIDS had "to plan their own strategies" and that they should be "involved at every level of decision-making" and "be included in all AIDS forums...to share their experiences and knowledge" [7]. The National Association of People with AIDS (NAPWA), was founded in 1983 "to implement the Denver Principles" and to give those affected by the epidemic "a voice in the policy and public health discussions that impacted their lives" [8]. In truth, transitioning

Ronald O. Valdiserri

rvaldis1@jhu.edu

David R. Holtgrave

dholtgrave@albany.edu

1 Department of Health, Behavior and Society, Johns Hopkins Bloomberg School of Public Health, Baltimore, USA

2 School of Public Health, University at Albany, SUNY, Rensselaer, NY 12144, USA from traditional treatment and disease control models that were primarily biomedical in nature with little direct input from affected communities to newer approaches that actively addressed "a range of scientific, social and political considerations" [9] was neither seamless nor effortless. But over time, the voices of affected communities were heard, and their perspectives helped to guide HIV research, program and policy decision-making [10].

One can highlight several major milestones that speak to the importance of community and governmental collaboration in response to America's HIV/AIDS epidemic. In 1989, to promote HIV education and risk reduction in racial/ethnic and sexual minority communities, the Centers for Disease Control and Prevention (CDC) began a program of direct support to CBOs in 27 metropolitan areas that were heavily affected by AIDS [11]. An important rationale for direct federal funding to support CBOs was the realization that HIV prevention efforts "must be appropriate for and responsive to the lifestyle, language, and environment of the members of that population" ([11], p. 704). Funders also hoped to identify innovative, community-derived prevention models that could be disseminated to other jurisdictions. CDC recognized that while CBOs might possess the commitment and enthusiasm to respond to the HIV/AIDS epidemic, for some, their organizational capacity to do so might pose limitations. Therefore, in 1988 the agency initiated a grant program to support national and regional racial and ethnic minority organizations to provide technical and capacity-building assistance to CBOs involved in HIV prevention activities [12]. In its first round of funding, four organizations serving racial and ethnic minority populations were selected along with one organization serving persons who inject drugs [12]. CDC's commitment to support affected communities' capacity to respond to HIV has remained steadfast, albeit the program has evolved over the course of the epidemic [13]; current providers of capacity-building technical assistance now include academic organizations and health departments in addition to non-governmental organizations [14].

In the second decade of America's HIV/AIDS epidemic, affected communities assumed a major, new role in 
the planning and implementation of federally funded HIV prevention activities. Findings from a number of program assessments conducted inside and outside of government, in addition to the availability of fiscal year 1994 Congressional budget support, led to the launch of a new, nationwide process designed to improve HIV prevention programs by making them more responsive to current and emerging epidemiologic trends, more relevant to affected communities and more effective in outcome, by employing proven, science-based interventions [15]. The new process was dubbed HIV Prevention Community Planning and states and localities receiving federal HIV prevention funds were required to convene planning groups that included community representatives, so that setting priorities for HIV prevention resources would be a shared responsibility of government (in this instance, state and local health departments) and the communities for whom the prevention activities were intended [15].

This new planning process was not without substantial implementation challenges, including the administrative and logistical demands of participatory planning, gaps in scientific information required for decision making (e.g., a dearth of cost-effectiveness data), difficulties agreeing on decision making rules for setting prevention priorities, and communication gaps between HIV Prevention Community Planning Groups and other relevant planning bodies such as Ryan White Planning Councils [16-18]. Challenges and shortcomings notwithstanding, a strong case can be made that HIV Prevention Community Planning represented a major step forward in America's response to its AIDS epidemic, by empowering communities affected by HIV to share decision-making with those governmental agencies that were charged with preventing further spread of the virus. And in the decades since, community empowerment and community engagement have come to be recognized as key strategies for promoting population health and resolving health disparities [19, 20].

Partnerships between community and government are not limited to the realm of HIV prevention. Such collaborations have also played a crucial role in the development and scale-up of systems of care for persons living with HIV. The federally-funded Ryan White HIV/AIDS Program (RWHAP), which now provides direct health care and support services for over half of all people diagnosed with HIV in the US [21], was first authorized some 9 years after the epidemic initially emerged [22]. The record shows that during the early years of the American epidemic, federal government was "slow to develop targeted programs to provide care" for persons sickened by the virus [22]. Nor was the US Congress quick to enact legislation responding to the crisis, despite multiple hearings on the impact of AIDS throughout the mid-1980s [23]. All of that changed in 1990, with the passage of the Comprehensive AIDS Resources Emergency
(CARE) Act, also known as the Ryan White CARE Act [22]. The passage of the CARE Act, along with much of its legislative content, has been attributed to the successful collaboration between a coalition of non-governmental organizations and elected officials in Congress [23].

NORA, the National Organizations Responding to AIDS coalition, was composed of over 100 diverse non-governmental organizations - several of which had strong roots in the various communities affected by the AIDS epidemic [23]. NORA was convened in the fall of 1989 "expressly to facilitate lobbying efforts on behalf of AIDS initiatives" and many of its core members had previously worked together on efforts to pass supportive legislation for persons living with disabilities ([23], p. 36). NORA's savvy efforts, including their effective collaboration with Congressional leaders, helped to garner bipartisan support for and eventual passage of the CARE Act of 1990, which has been reauthorized four times since its initial enactment [23].

As noted above, community leaders played a decisive role in the successful passage of the CARE Act. But this is not their only legacy when it comes to a reckoning of the evolution of quality HIV care in the US. Even prior to the passage of this landmark legislation, one can find prominent examples of communities' contribution to our understanding of the elements of care necessary to meet the varied needs of persons living with AIDS. In the days prior to effective antiretroviral treatment, community-based AIDS service providers demonstrated the importance of delivering comprehensive care that encompassed support services for the daily activities of living, including psychosocial support through the provision of "buddies" [24]. And community activists did not shy away from calling-out existing services that were "judged to be either inadequate or insensitive to the needs of people with HIV infection or AIDS" ([25], p. 421). These actions, carried-out in multiple cities across the US, helped to shape our understanding that affected communities must be involved in the design and delivery of the services being developed to provide for their needs [26]. That legacy has been enshrined in the CARE Act. For both part A of the RWHAP, providing support to metropolitan areas severely affected by HIV/AIDS, and part B, which provides grants to states and territories, the legislation requires a participatory planning process in which consumers (in this instance persons living with HIV) have a voice in establishing priorities for the allocation of funds [27, 28].

Taking into consideration the efforts of ACT UP and the Treatment Action Group (TAG) illustrates that the trajectory of HIV/AIDS research has also been shaped by the voices of community. One of the most obvious examples is the significant impact of community activism on the HIV drug approval process, with regard to broadening patient and community involvement in developing and testing new drugs, shortening the overall development and review 
process for new drugs and increasing access to promising new drugs before their official approval by the Food and Drug Administration (FDA) [29]. Impelled by the demands of people living with HIV and those at risk for infection, in 1989 the National Institutes of Health (NIH) launched the Community Programs for Clinical Research on AIDS (CPCRA) a community-based clinical trials network madeup of community providers caring for persons with HIV - as opposed to university-based researchers, the more traditional partners in clinical trials $[29,30]$. The CPCRA "represented the first time in the history of the National Institutes of Health that a CAB (Community Advisory Board) was required to help design and implement research studies" ([30], p. 292). By 1990, the NIH also required that each of its university-based research partners conducting HIV clinical trials (i.e., the AIDS Clinical Trial Group), constitute and maintain a $\mathrm{CAB}$, to inform research design and implementation and to promote communication between community representatives and university-based researchers [31]. Since that time, NIH has implemented a number of policies and programs to ensure that "the community always has a seat at the table," further underscoring the importance of this critical collaboration [32].

Whether in the area of HIV prevention, care or research, one can point to positive outcomes that have resulted from the active involvement of affected communities working alongside government partners. That's not to say that these results have been achieved without considerable effort. Regardless of one's organizational affiliation or viewpoint, those who have been involved in collaborative decision-making understand that it cannot be manufactured nor can it be faked; it takes energy and time to build relationships and reach a stage where decisions are supported across various partners, even in the face of strikingly different perspectives [33]. In short, learning the lessons of authentic community participation in HIV program, policy and research decisionmaking has been a hard-earned process, the insights from which should be kept foremost in the minds of all government officials who are seeking to end the HIV epidemic in America $[34,35]$.

As currently articulated, the recently announced federal plan to end HIV in the US calls for the rapid detection of emerging clusters of new HIV infections, prompt diagnosis and rapid treatment of all who are currently infected with HIV and widespread use of pre-exposure prophylaxis (PrEP) to prevent new HIV infections among those who are vulnerable [34]. Based on accepted epidemiologic principles and given our current state of biomedical knowledge, these are, indeed, appropriate actions that, if effectively implemented, have the potential to end epidemic HIV transmission in the US. But continuing with the theme of community collaboration and borrowing from the paradigm of logic modeling [36], one cannot ignore the community-specific constraints that might impact these recommended actions or minimize the influence that policy and economic context will exert on the proposed plan. And it is precisely because of these realities that active, authentic community participation in all phases of the federal plan to end HIV is critical to its success.

Asserting that active community participation is necessary to end the HIV epidemic in America is consistent with the broader principle of health equity which recognizes and embraces the fundamental importance of empowering communities to improve their own health $[37,38]$. A foundational principle of health equity arises from the realization that "the burdens of disease and poor health and the benefits of well-being and good health are inequitably distributed" [38]. This is certainly the case when we consider the demographic, social, economic and geographic disparities that HIV manifests in the US [39]. To achieve health equity, then, is to reach a state in which "no one is denied the possibility to be healthy for belonging to a group that has historically been economically/socially disadvantaged" ([40], p. 7). Given the multiple determinants that shape health outcomes and contribute to health disparities, it follows that multiple sectors and various partners have to be involved in defining and implementing the approaches employed to improve health-or in this specific instance, to end HIV in the US. And affected communities are key partners in this undertaking.

It is likely that some readers of this commentary may view any directive endorsing the active involvement of affected communities in governmental efforts to end HIV as a pro forma reaction, a nod to past responses to the epidemic. Where it exists, such reductionist thinking ignores the growing body of evidence underscoring the need to address complexity in population health interventions. As noted by Hawe, complexity results "from the interactions among many component parts" and "is a property of both the intervention and the context (or system) into which it is placed" ([41], p. 307). Stated another way, intervention effects are "attenuated or amplified by the characteristics and dynamic evolution of the system (context) in which it is implemented" ([42], p. 319). Ergo, for maximum effectiveness, HIV prevention and treatment interventions must account for salient contextual factors both before and during their implementation. Merely acknowledging that social and economic determinants influence health is not sufficient. To truly understand the breadth and relative importance of contextual issues, we must seek-out and attend to the first-hand knowledge of those individuals and communities who we are trying to reach with these interventions.

A brief example illustrates this point. No one who is cognizant of recent biomedical advances doubts the efficacy of PrEP in preventing HIV infection [43] nor would they question PrEP's inclusion as one of the "pillars" in the recently 
announced plan to end HIV in the US [34]. And while awareness and use of PrEP among men who have sex with men (MSM), a key target population, has increased in recent years, PrEP use remains low-especially among black and Hispanic men [44]. This suboptimal use speaks to the reality that many factors, beyond lack of awareness, can influence the uptake of PrEP by MSM who could benefit from its protective effects [45]. For example, several investigators have documented that medical mistrust and perceptions of racism and homonegativity in healthcare settings represent significant structural barriers to PrEP use among black MSM [46-48]. Add to this the fact that public trust in government among all racial and ethnic groups, including nonHispanic whites, remains at historic lows [49] and one might reasonably predict that expanding physical access to PrEP, by itself, may not address all of the consequential factors impeding its use. To this point, ethnographers in New York City employed participant observation, key informant and in-depth interviews of Black MSM to better understand the factors that influence their engagement in HIV prevention services [50]. They found that widespread fear and mistrust of public and social institutions hindered engagement with HIV prevention services and that the men expressed the need for "safe spaces" where they could address other important social and economic needs in their lives, not just HIV [50].

In conclusion, we contend that without the active involvement of communities affected by HIV it will not be possible to end the virus' epidemic spread in the US. How this involvement is structured and sustained will vary depending upon local factors and circumstances. But the role of community must not be limited to identifying issues and problems; they must also be actively involved in identifying and implementing solutions. This does not mean that we turn our backs on science or that we fail to adopt knowledgebased interventions. To the contrary, it means that we understand-from the perspective of affected communities-how their lived experience shapes the context of HIV in their daily lives and that we implement and adapt evidence-based HIV prevention and treatment interventions that they deem to be relevant and appropriate.

Several weeks prior to the articulation of the federal government's new plan to end HIV, a broad-based community coalition published a detailed set of recommendations to end the US HIV epidemic by 2025 [51]. Not unexpectedly, the community-derived plan places substantial emphasis on addressing the structural inequities and socially-derived vulnerabilities, such as racism, homophobia, and transphobia, that continue to fuel the HIV epidemic. In fact, the plan's authors warn us that if we fail to confront these powerful determinants, "we will only continue to perpetuate disparities and injustices in HIV" ([51], p. 17). Without doubt, advances in scientific knowledge have allowed us to realistically envision a possible end to HIV in America. But this can only happen if we embrace and empower the very communities who are affected by this epidemic.

\section{References}

1. Allen SM, Mor V, Fleishman JA, Pierce JD. The organizational transformation of advocacy: growth and development of AIDS community-based organizations. AIDS Public Policy. 1995;10(1):48-59.

2. Andriote JM. Victory deferred: how AIDS changed gay life in America. Chicago: University of Chicago Press; 1999.

3. Valdiserri RO. HIV/AIDS in historical profile. In: Valdiserri RO, editor. Dawning answers: how the HIV/AIDS epidemic has helped to strengthen public health. New York: Oxford University Press; 2003.

4. Jones C, Dawson J. A vision of the quilt. In: Stitching a revolution. San Francisco: Harper Collins; 2000.

5. Valdiserri RO. Planning and implementing AIDS prevention programs: a case study approach. In: Valdiserri RO, editor. Preventing AIDS: the design of effective programs. New Brunswick: Rutgers University Press; 1989.

6. Altman D. Power and community: organizational and cultural responses to AIDS. London: Taylor and Francis; 1999.

7. People with AIDS Committee. The Denver principles. http://www. data.unaids.org/pub/externaldocument/2007/gipa1983denverp rinciples_en.pdf. Accessed 23 Feb 2019.

8. National Minority AIDS Council. HIV/AIDS Movement has lost historic voice in NAPWA. 15 Feb 2013. www.nmac.org/hivaidsmovement-has-lost-historic-voice-in-napwa. Accessed 4 March 2019.

9. Brandt AM. AIDS in historical perspective: four lessons from the history of sexually transmitted diseases. Am J Public Health. 1988;78(4):367-71.

10. Valdiserri RO. HIV AIDS' contribution to community mobilization and health planning efforts. In: Valdiserri RO, editor. Dawning answers: how the HIV/AIDS epidemic has helped to strengthen public health. New York: Oxford University Press; 2003.

11. Bailey ME. Community-based organizations and CDC as partners in HIV education and prevention. Public Health Rep. 1991;106(6):702-8.

12. Holman PB, Jenkins WC, Gayle JA, Duncan D, Lindsey BK. Increasing the involvement of national and regional racial and ethnic minority organizations in HIV information and education. Public Health Rep. 1991;106(6):687-94.

13. Taveras S, Duncan T, Gentry D, Gilliam A, Kimbrough I, Minaya J. The evolution of the CDC HIV Prevention CapacityBuilding Assistance Initiative. J Public Health Manag Pract. 2007;Suppl:S8-15.

14. National Capacity Building Assistance (CBA) Provider Network (CPN) Resource Center. Find a CBA provider. https://cbaprovide rs.org/providers/index.aspx. Accessed 28 Feb 2019.

15. Valdiserri RO, Aultman TV, Curran JW. Community planning: a national strategy to improve HIV prevention programs. J Community Health. 1995;20(2):87-100.

16. Holtgrave DR, Valdiserri RO. Year one of HIV prevention community planning: a national perspective on accomplishments, challenges, and future directions. J Public Health Manag Pract. 1996;2(3):1-9.

17. Schietinger H, Coburn J, Levi J. Community planning for HIV prevention: findings from the first year. AIDS Public Policy. 1995;10(3):140-7. 
18. Pinkerton SD, Holtgrave DR, Willingham M, Goldstein E. Costeffectiveness analysis and HIV prevention community planning. AIDS Public Policy. 1998;13(3):115-27.

19. Thompson B, Molina Y, Viswanath K, Warnecke R, Prelip ML. Strategies to empower communities to reduce health disparities. Health Aff. 2016;35(8):1424-8.

20. Cyril S, Smith BJ, Possamai-Inesedy A, Renzaho AM. Exploring the role of community engagement in improving the health of disadvantaged populations: a systematic review. Glob Health Action. 2015;8:29842.

21. Mandsager P, Marier A, Cohen S, Fanning M, Hauck H, Cheever LW. Reducing HIV-related health disparities in the health resources and services administration's Ryan White HIV/AIDS Program. Am J Public Health. 2018;108(S4):S246-50.

22. Parham D, Conviser R. A brief history of the Ryan White CARE Act in the USA and its implications for other countries. AIDS Care. 2002;14(S1):S3-6.

23. Poindexter CC. Promises in plague: passage of the Ryan White Comprehensive AIDS Resources Emergency Act as a case study for legislative action. Health Soc Work. 1999;24(1):35-41.

24. Kawata PA, Andriote JM. NAN - a national voice for community-based services to persons with AIDS. Public Health Rep. 1988;103(3):299-304

25. McCann K. Care in the community and by the community. AIDS Care. 1990;2(4):421-4

26. Dilley JW. Implications for the San Francisco model of care. AIDS Care. 1990;2(4):349-52.

27. Health Resources and Services Administration, HIV/AIDS Bureau. Ryan White HIV/AIDS Program: Part A manual. https:// hab.hrsa.gov/sites/default/files/hab/Global/happartamanual2013. pdf. Accessed 5 March 2019.

28. Health Resources and Services Administration, HIV/AIDS Bureau. Ryan White HIV/AIDS Program: Part B manual. https:// hab.hrsa.gov/sites/default/files/hab/About/RyanWhite/habpartbma nual2013.pdf. Accessed 5 March 2019.

29. Nichols E, Institute of Medicine Roundtable for the Development of Drugs and Vaccines Against AIDS. Expanding access to investigational therapies for HIV infection and AIDS: March 12-13, 1990 conference summary. Washington, DC: National Academies Press; 1991. https://www.ncbi.nlm.nih.gov/books/NBK234125/. Accessed 7 March 2019.

30. Cox LE, Rouff JR, Svendsen KH, Markowitz M, Abrams DI. Community Advisory Boards: their role in AIDS clinical trials. Health Soc Work. 1998;23(4):290-7.

31. Strauss RP, Sengupta S, Quinn SC, et al. The role of Community Advisory Boards: involving communities in the informed consent process. Am J Public Health. 2001;91(12):1938-43.

32. Dieffenbach C. Community engagement in NIAID's HIV/AIDS Clinical Trials Network. September 29, 2011. www.hiv.gov/blog/ community-engagement-in-niaids-hivaids-clinical-trials-netwo rks. Accessed 7 March 2019.

33. Thomson AM, Perry JL. Collaboration processes: inside the black box. Public Adm Rev. 2006;66(s1):20-32.

34. Fauci AS, Redfield RR, Sigounas G, Weahkee MD, Giroir BP. Ending the HIV epidemic: a plan for the United States. J Am Med Assoc. 2019. https://doi.org/10.1001/jama.2019.1343.

35. Azar A. Ending the HIV epidemic: a plan for America. February 5, 2019. www.hhs.gov/blog/2019/02/05/ending-the-hiv-epidemica-plan-for-america.html. Accessed 7 Feb 2019.

36. Center for Community Health and Development at the University of Kansas. Community tool box: developing a logic model. https ://ctb.ku.edu/en/table-of-contents/overview/models-for-commu nity-health-and-development/logic-model-development/main. Accessed 12 March 2019.
37. Trujillo MD, Plough A. Building a culture of health: a new framework and measures for health and health care in America. Soc Sci Med. 2016;165:206-13.

38. National Academies of Sciences, Engineering and Medicine. Communities in action: pathways to health equity. Washington, DC: National Academies Press; 2017.

39. Truman BI, Mermin JH, Dean HD. Measuring progress in reducing disparities in HIV, tuberculosis, viral hepatitis, and sexually transmitted diseases in the United States: a summary of this theme issue. Am J Public Health. 2018;108(S4):S240-1.

40. Braveman P. What are health disparities and health equity? We need to be clear. Public Health Rep. 2014;129(Suppl 2):5-8.

41. Hawe P. Lessons from complex interventions to improve health. Annu Rev Public Health. 2015;36:307-23.

42. Minary L, Alla F, Cambon L, Kivits J, Potvin L. Addressing complexity in population health intervention research: the context/intervention interface. J Epidemiol Community Health. 2018;72:319-23.

43. Baeten JM. Amplifying the population health benefits of PrEP for HIV prevention. J Infect Dis. 2018;217:1509-11.

44. Finlayson T, Cha S, Denson D, Trujillo L, Xia M, Prejean J, Wejnert C. Changes in PrEP awareness and use among men who have sex with men, 2014 VS 2017. In: CROI conference 2019, abstract \# 972. www.croiconference.org/sessions/changes-hivprep-awareness-and-use-among-men-who-have-sex-with-men2014-vs-2017. Accessed 15 March 2019.

45. Valdiserri RO, Holtgrave DR. Pre-exposure prophylaxis for HIV infection: preventing disease or promoting sexual health? J Community Health. 2019. https://doi.org/10.1007/s10900-018-00616 -3 .

46. Quinn K, Dickson-Gomez J, Zarwell M, Pearson B, Lewis M. "A Gay Man and a Doctor are Just like, a Recipe for Destruction": how racism and homonegativity in healthcare settings influence PrEP uptake among young Black MSM. AIDS Behav. 2018. https ://doi.org/10.1007/s10461-018-2375-z.

47. Cahill S, Taylor SW, Elesser SA, Mena L, Hickson D, Mayer KH. Sigma, medical mistrust, and perceived racism may affect PrEP awareness and uptake in Black compared to White gay and bisexual men in Jackson, Mississippi and Boston, Massachusetts. AIDS Care. 2017;29:1351-8.

48. Eaton LA, Kalichman SC, Price D, Finneran S, Allen A, Maksut J. Stigma and conspiracy beliefs related to pre-exposure prophylaxis (PrEP) and interest in using PrEP among Black and White men and transgender women who have sex with men. AIDS Behav. 2017;21:1236-46.

49. Pew Research Center. Public trust in government, 1958-2017. December 14, 2017. www.people-press.org/2017/12/14/publicvtrust-in-government-1958-2017/. Accessed 4 March 2019.

50. Garcia J, Parker C, Parker RG, Wilson PA, Philbin MM, Hirsch JS. "You're Really Gonna Kick Us All Out?": sustaining safe spaces for community-based HIV prevention and control among Black men who have sex with men. PLoS ONE. 2015;10(10):e0141326. https://doi.org/10.1371/journal.pone.0141326.

51. AIDS United and Act Now End AIDS Coalition. Ending the HIV epidemic in the United States: a roadmap for federal action. November 30, 2018. www.aidsunited.org/data/files/site_18/ Policy/Ending_the_HIV_Epidemic_U.S._Roadmap_for_Feder al_\%Action.Final.pdf. Accessed 1 Dec 2018.

Publisher's Note Springer Nature remains neutral with regard to jurisdictional claims in published maps and institutional affiliations. 